Www.jmscr.igmpublication.org

Impact Factor (SJIF): 6.379

Index Copernicus Value: 79.54

ISSN (e)-2347-176x ISSN (p) 2455-0450

crossrefDOI: https://dx.doi.org/10.18535/jmscr/v6i10.164

Journal Of Medical Science And Clinical Research

\title{
A Statistical Analysis-Usefulness of Resistive Index and Vascularity patterns to differentiate benign from malignant breast lesions using Color Doppler Ultrasound
}

\begin{abstract}
Authors
Dr Pearly Stephen ${ }^{1 *}$, Prof. Dr Adaikkappan ${ }^{2}$

${ }^{* 1}$ Post Graduate Student, Department of Radiodiagnosis, RMMCH, Annamalai University,

Chidambaram - 608 002, Tamil Nadu, India

${ }^{2}$ Professor and Head of the Department, Department of Radiodiagnosis, RMMCH, Annamalai University, Chidambaram - 608 002, Tamil Nadu, India.

Abstract

Objectives: To establish the usefulness of Resistive Index and vascularity patterns using Color Doppler Ultrasound (CDUS) in differentiating benign from malignant breast lesions and to correlate the imaging findings with pathologic results.

Results: Significantly increased values of $R I>0.73$, Peak systolic velocity $>25 \mathrm{~cm} / \mathrm{sec}$ along with the presence of more penetrating vessels which are radially arranged and show chaotic vascularity are characteristic features of malignant breast lesion. When RI is around 0.66-0.73, Peak systolic velocity $<25 \mathrm{~cm} / \mathrm{sec}$ along with the vascularity along the tumor margins in a peripheral net pattern, they are usually features of benign lesions. In this way we can differentiate benign from malignant breast pathologies and also categorise indeterminate lesions into either of them.

Conclusion: Color Doppler sonography is an ideal imaging technique that can be used in conjunction with basic imaging modalities such as mammography and grey scale imaging ultrasonography, as a non invasive method for confirmatory diagnosis of breast lesions. Some of the variables have been statistically analysed to establish its unique role in better evaluation of breast cancers. It's based on the fact that most malignant lesions show more neovascularisation than benign lesions when compared to the normal breast parenchyma.
\end{abstract}

Keywords: Color Doppler sonography, Resistive Index (RI), Peak systolic velocity (PSV).

\section{Introduction}

Breast cancer is the leading cause of death among women accounting for $14 \%$ of cancer related deaths worldwide. Amidst increasing awareness and sensitisation, trend of early detection of malignancies through various imaging modalities have undergone a tremendous upgradations.

For long mammography has remained unchallenged as the basic screening method for breast cancer. There are certain limitations of mammography in young women, pregnancy because of radiation hazards, women who are obese and have dense breasts, wherein the detection rate through mammography declines to $38 \%$.Routine imaging with ultrasound alongside mammography can improvise the diagnostic accuracy to $75 \%$ whereas the sensitivity of only mammography is $(50 \%)^{[1]}$. Even small breast 
lesions which go unnoticed in mammography films can be identified by ultrasound imaging by grey scale ${ }^{[2]}$. Since there are challenges in diagnosing benign and malignant lesions of the breast and the term indeterminate is more often used, a single imaging modality may not be confirmatory. This is where Color Doppler Ultrasonogram helps us to characterise benign and malignant breast lesions based on a different perspective. It defines how benign and malignant lesions differ the morphology, distribution of vessels and the flow impedance $e^{[3,4]}$.

Even though a constellation of other imaging techniques and principles such as sonoelastography, 3D Doppler, tissue harmonics, tomosynthesis, MRI have become available, mammography still remains the initial imaging investigation to assess breast lesions ${ }^{[5,6]}$. There is still more room for improvisations when vascularity and flow related parameters are explored and taken into consideration as a part of the routine imaging for better diagnosis ${ }^{[7]}$.

\section{Materials and Method}

For our study 40 patients who were willing to be subjected for the imaging investigations were enrolled. On the basis of the histopathology reports two groups were formed comprising 20 benign cases and 20 malignant cases. The study population were of the age group of 20 years to 60 years. The study was approved by the Department of Radiology, Rajah Muthiah Medical College and conducted during the period of July 2017 to Sep 2018. Informed written consent was obtained from all patients.

\section{Inclusion Criteria}

Inclusion criteria for the sample was any patient with solid space occupying or palpable breast lesions in women of the age group 20-60 years were identified clinically -subjected to ultrasound, mammography and subsequently FNAC.

\section{Exclusion Criteria}

Pregnancy

Patients with previous operative history for a breast cancer
Cases with inconclusive cytology reports due to inadequate tissue sampling

Patients who did not turn up with their FNAC reports

Patients who could not be tracked or could not be contacted further

\section{Positioning and Technique}

The patient was positioned comfortably in supine position, slightly rotated away from the side of interest so that the breast parenchyma is uniformly spread over the anterior chest wall. The other arm was positioned behind the head. A systematic approach was followed while using the transducer in a radial fashion in the clockwise direction. Axial as well as sagittal images were acquired. After documenting the morphologic characteristics on grey scale sonography, color Doppler was done using LN5-12 linear transducer. An adequate time of 10 to 20 minutes were taken to perform the scan depending on the lesion.

\section{Results}

Table -1: Doppler Criteria - Number of blood vessels

\begin{tabular}{|l|c|c|}
\hline No. of Vessels & Benign & Malignant \\
\hline 0 & 30 & 5 \\
\hline 1 & 50 & 0 \\
\hline 2 & 10 & 20 \\
\hline 3 & 5 & 10 \\
\hline$>4$ & 5 & 65 \\
\hline
\end{tabular}

In our study group of the 40 cases, 20 benign cases and 20 malignant cases were enrolled. 14 (70\%) of the benign cases showed vascularity of which $13(65 \%)$ had less than 4 vessels. Whereas $13(65 \%)$ of the malignant lesions showed more than 4 vessels. Thereby malignant lesions showed more feeding vessels when compared to the benign lesions ${ }^{[8]}$. 


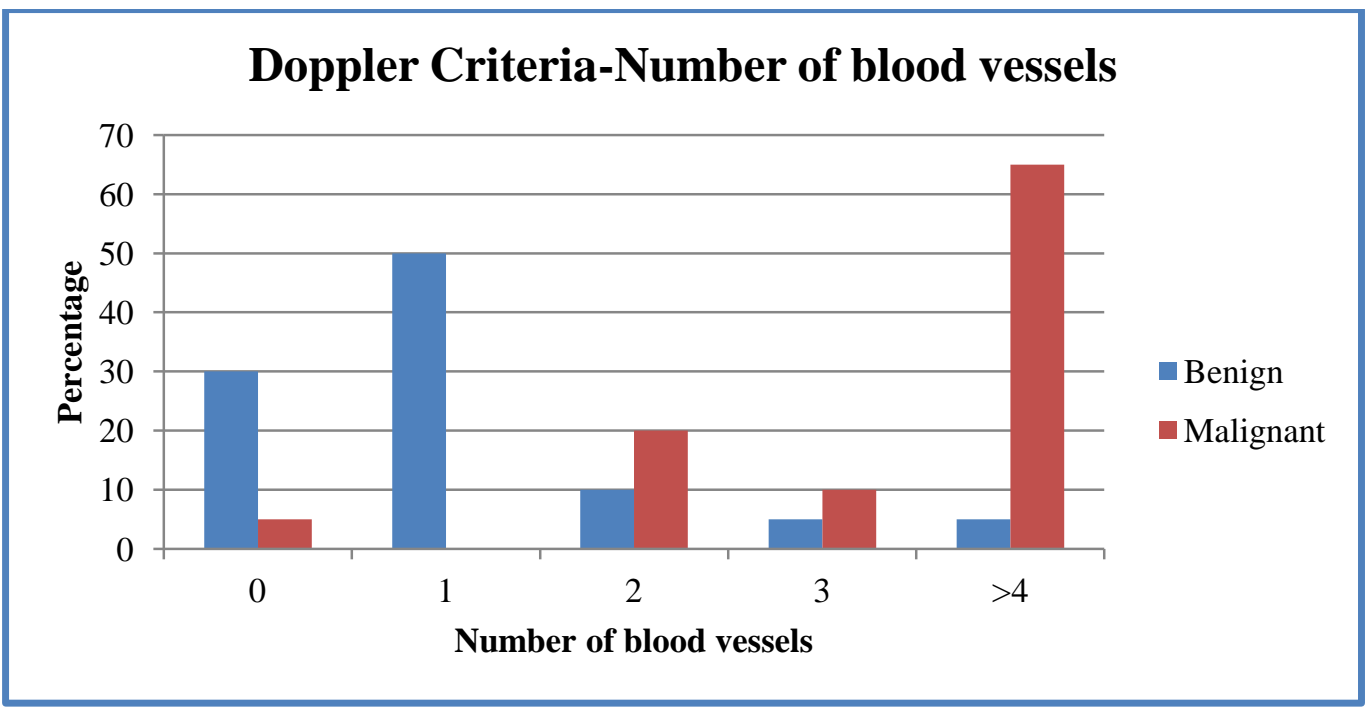

Table - 2: Doppler Vascularity Pattern

\begin{tabular}{|l|c|}
\hline Morphology of vessels & Number of vessels \\
\hline Smooth Vessels & 9 \\
\hline Tortuous Vessels & 4 \\
\hline Chaotic Vascularity & 1 \\
\hline Absence of Vascularity & 6 \\
\hline
\end{tabular}

Of the $14(70 \%)$ benign lesions which showed vascularity, 9(45\%) showed smooth vessels, only $4 \quad(20 \%)$ showed tortuous vessels and chaoticvascularity was demonstrable in $5 \%$ of the cases. Most benign lesions have less metabolic demands, require less neovascularization and usually do not distort the microvasculature ${ }^{[9]}$.

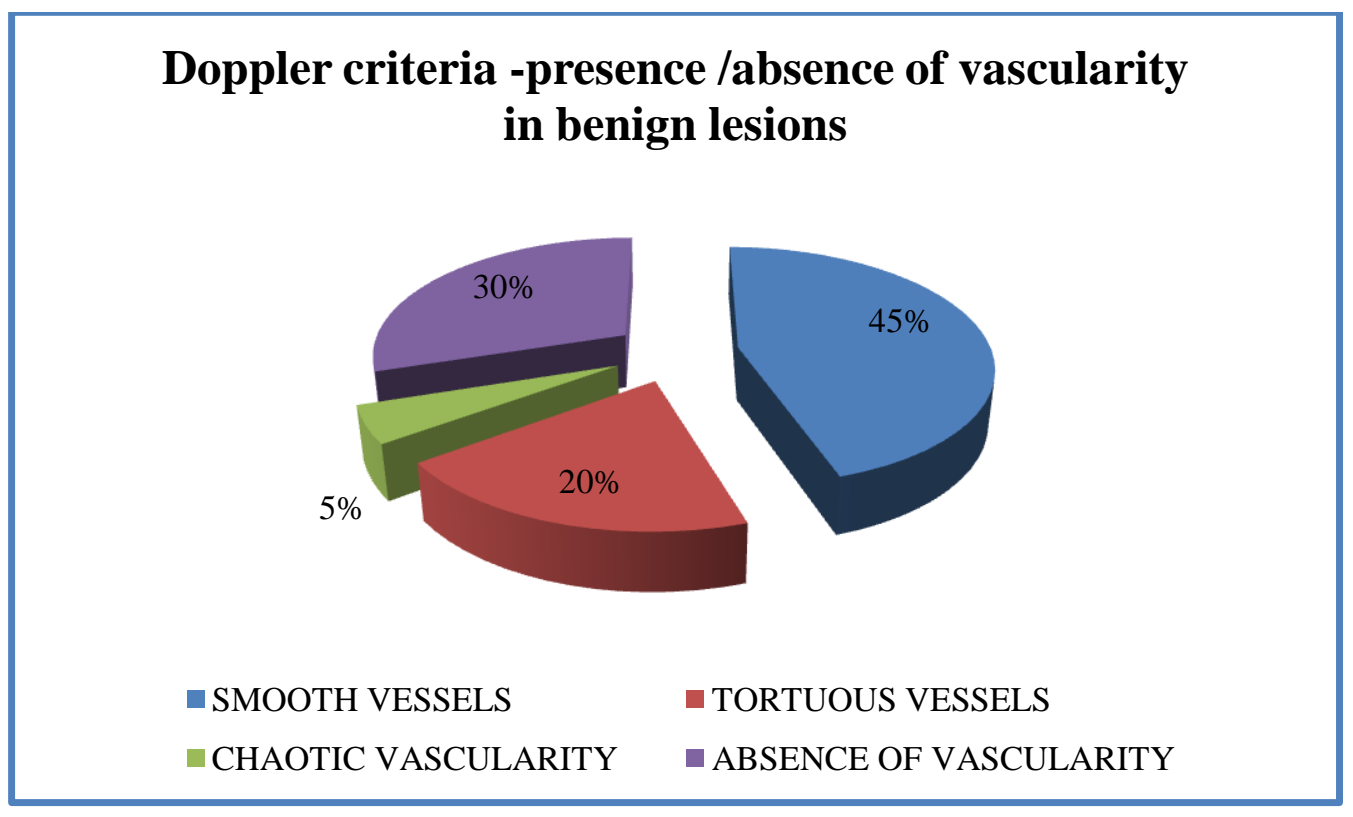

Table -3: Doppler criteria-Presence/Absence of vascularity in malignant lesions

\begin{tabular}{|l|c|}
\hline $\begin{array}{l}\text { Morphology and } \\
\text { Distribution of vessels }\end{array}$ & Number of vessels \\
\hline Smooth vessels & 5 \\
\hline Absence of vascularity & 2 \\
\hline Tortuous vessels & 11 \\
\hline Chaotic vascularity & 2 \\
\hline
\end{tabular}

Of the $18(90 \%)$ malignant lesions which showed vascularity, 11(55\%) showed tortuous vessels, only $5(25 \%)$ showed smooth vessels and chaotic vascularity was seen in $10 \%$ of the cases. Most malignancies have extensive neovascularization as they grow and proliferate ${ }^{[10]}$. Penetrating vessels enter in a perpendicular fashion into the core of the lesion without traversing the capsule giving a spoke wheel pattern ${ }^{[11]}$. 


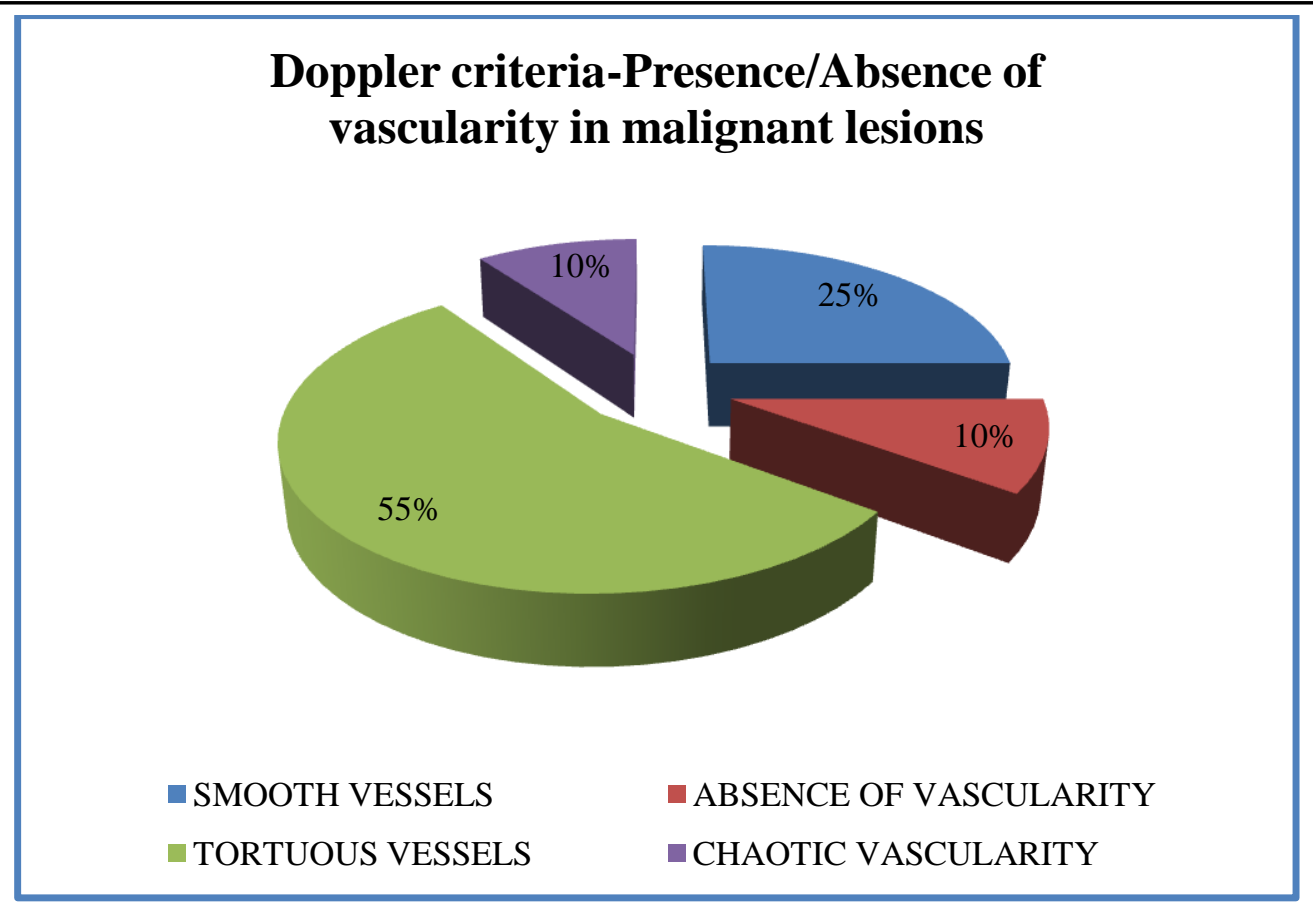

Table- 4: Doppler Waveform

\begin{tabular}{|l|l|l|}
\hline Type of Waveform & Benign & Malignant \\
\hline Low Impedance & 68 & 4 \\
\hline High impedance & 5 & 64 \\
\hline Turbulent & 11 & 25 \\
\hline Venous & 16 & 7 \\
\hline
\end{tabular}

It was demonstrated in this study that there was significantly lower flow impedance in $68 \%$ of the benign lesions and high impedance flow in $64 \%$ of the malignant lesions. The core of the lesion showed vessels with high peak systolic velocities and high resistive index whereas the periphery of the lesion showed low velocity flow with low resistive index. The venous pattern was seen in $16 \%$ of benign lesions and $7 \%$ of malignant lesions because of arterio-venous shunts ${ }^{[10]}$.

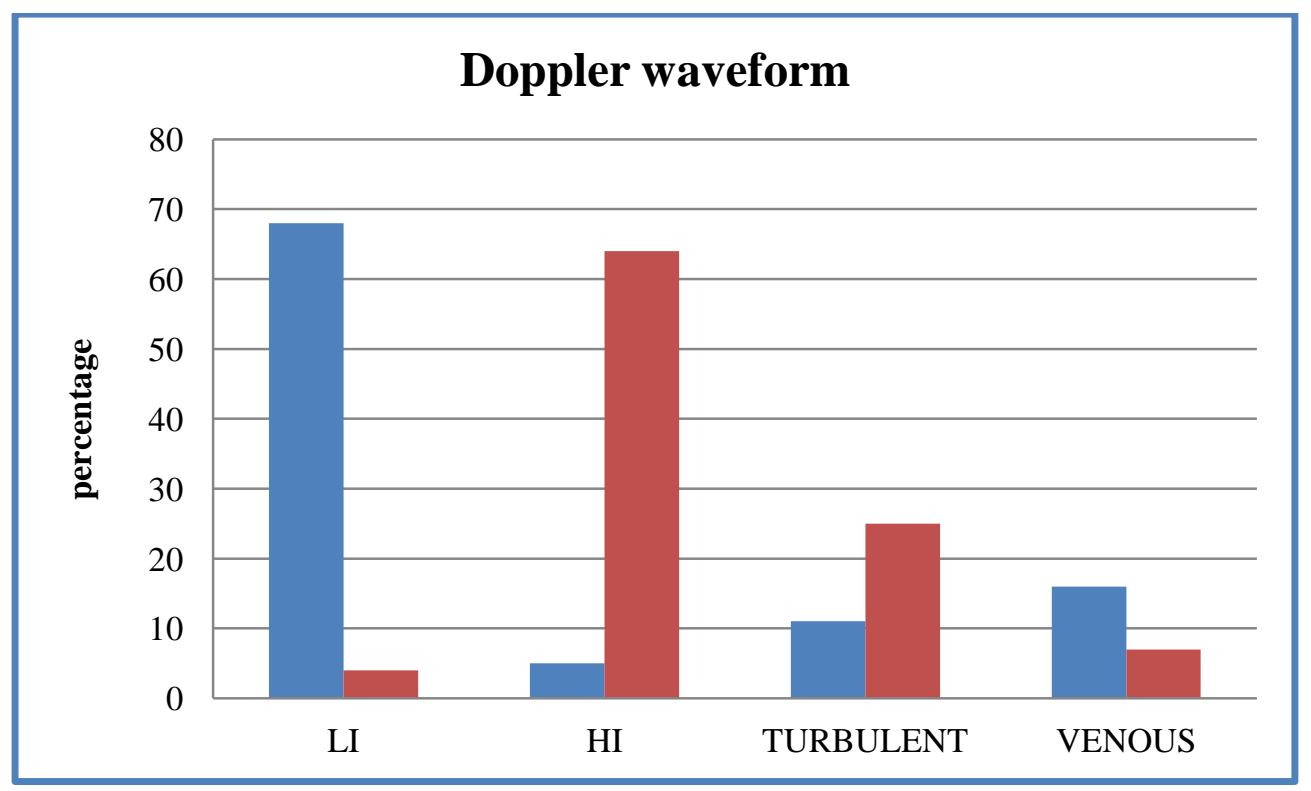


Table - 5: Doppler Vascularity Pattern

\begin{tabular}{|l|c|c|c|c|c|}
\hline & Central & Peripheral & Mixed & Capsular & No Vascularity \\
\hline Benign & 3 & 9 & 2 & 13 & 6 \\
\hline Malignant & 11 & 2 & 5 & 4 & 2 \\
\hline
\end{tabular}

In our study it was observed that $13(65 \%)$ benign lesions had trans-capsular vessels while only 4 (20\%) malignant cases showed capsular vessels. As already discussed 9 (45\%) of the benign lesions had predominantly peripheral net pattern of vessels but most malignant lesions in our study about 11 cases $(55 \%)$ showed predominantly central vascularity ${ }^{[12]}$.

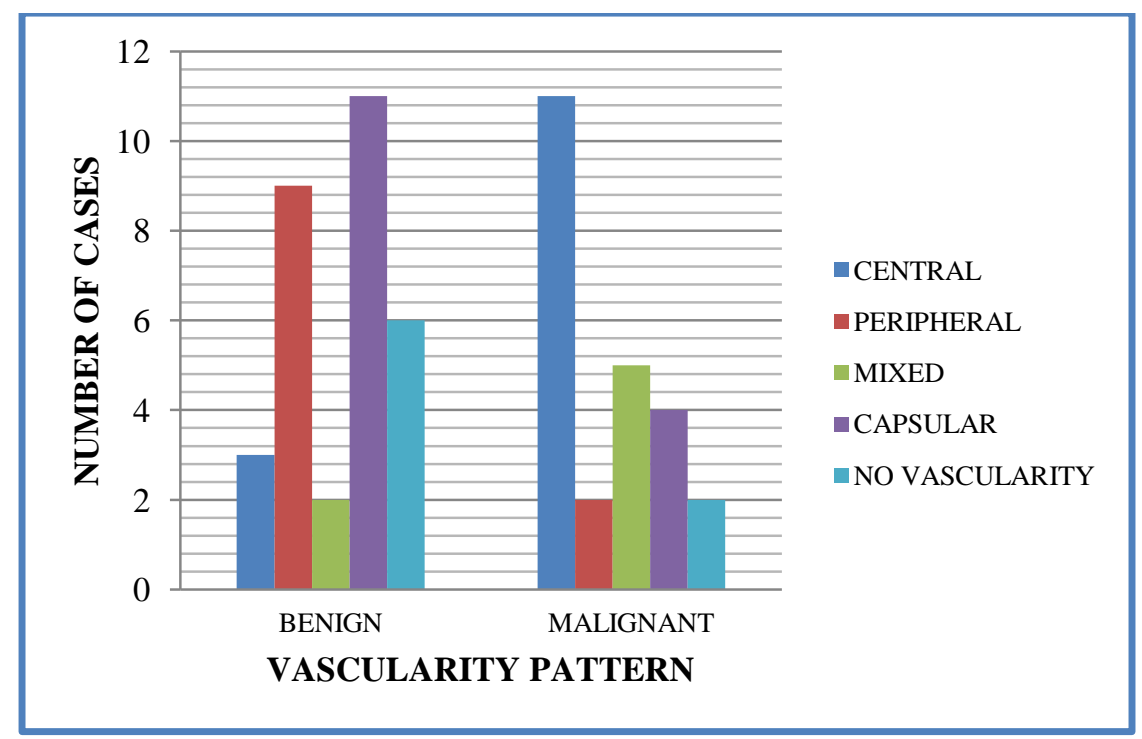

Table : Doppler - Resistive Index

\begin{tabular}{|l|c|c|}
\hline Resistive Index & Benign & Malignant \\
\hline 0.1 & 0 & 0 \\
\hline 0.2 & 0 & 0 \\
\hline 0.3 & 0 & 0 \\
\hline 0.4 & 0 & 0 \\
\hline 0.5 & 1 & 0 \\
\hline 0.6 & 11 & 2 \\
\hline 0.7 & 2 & 9 \\
\hline 0.8 & 1 & 6 \\
\hline 0.9 & 0 & 1 \\
\hline
\end{tabular}

In our study sample, benign lesions showed higher RI values in $12(60 \%)$ of the cases of mean 0.66 with a SD of 0.062. Malignant lesions showed higher RI values in $16(80 \%)$ of the cases of mean 0.73 with a SD of 0.083 .

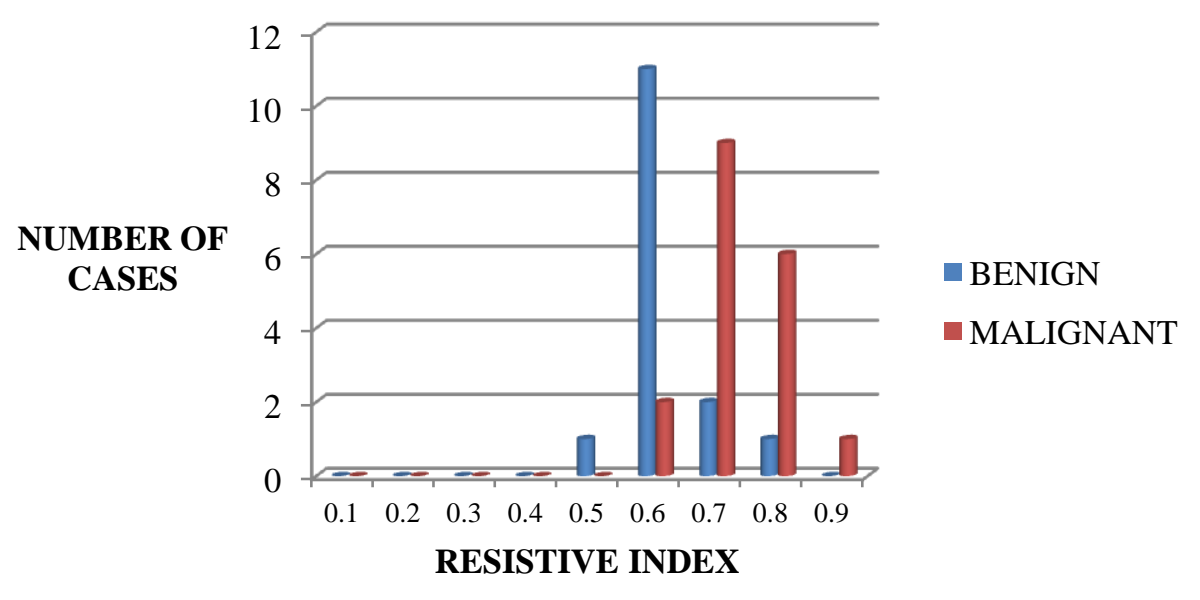




\section{JMSCR Vol||06||Issue||10||Page 980-987||October}

In our study sample, majority of the benign lesions showed relatively lower PSV values in 12 $(60 \%)$ of the cases of mean of 22. Malignant lesions showed higher PSV values in $16(80 \%)$ of the cases of mean value of 0.26 .

Table : Doppler - Resistive Index

\begin{tabular}{|l|c|c|}
\hline \multirow{2}{*}{ Patients } & \multicolumn{2}{|c|}{$\begin{array}{c}\text { Peak systolic velocity in } \\
\text { (cm / sec) }\end{array}$} \\
\cline { 2 - 3 } & Benign & Malignant \\
\hline 1 & 19 & 26 \\
\hline 2 & 21 & 28 \\
\hline 3 & 26 & NV \\
\hline 4 & NV & 25 \\
\hline 5 & 18 & 22 \\
\hline 6 & 30 & 28 \\
\hline 8 & NV & 28 \\
\hline 9 & 24 & 25 \\
\hline 10 & 25 & 30 \\
\hline 11 & 21 & NV \\
\hline 12 & 21 & 24 \\
\hline 13 & NV & 28 \\
\hline 14 & 28 & 25 \\
\hline 15 & NV & 30 \\
\hline 16 & 18 & 20 \\
\hline 17 & 22 & 26 \\
\hline 18 & NV & 25 \\
\hline 19 & NV & 28 \\
\hline 20 & 26 & 22 \\
\hline
\end{tabular}

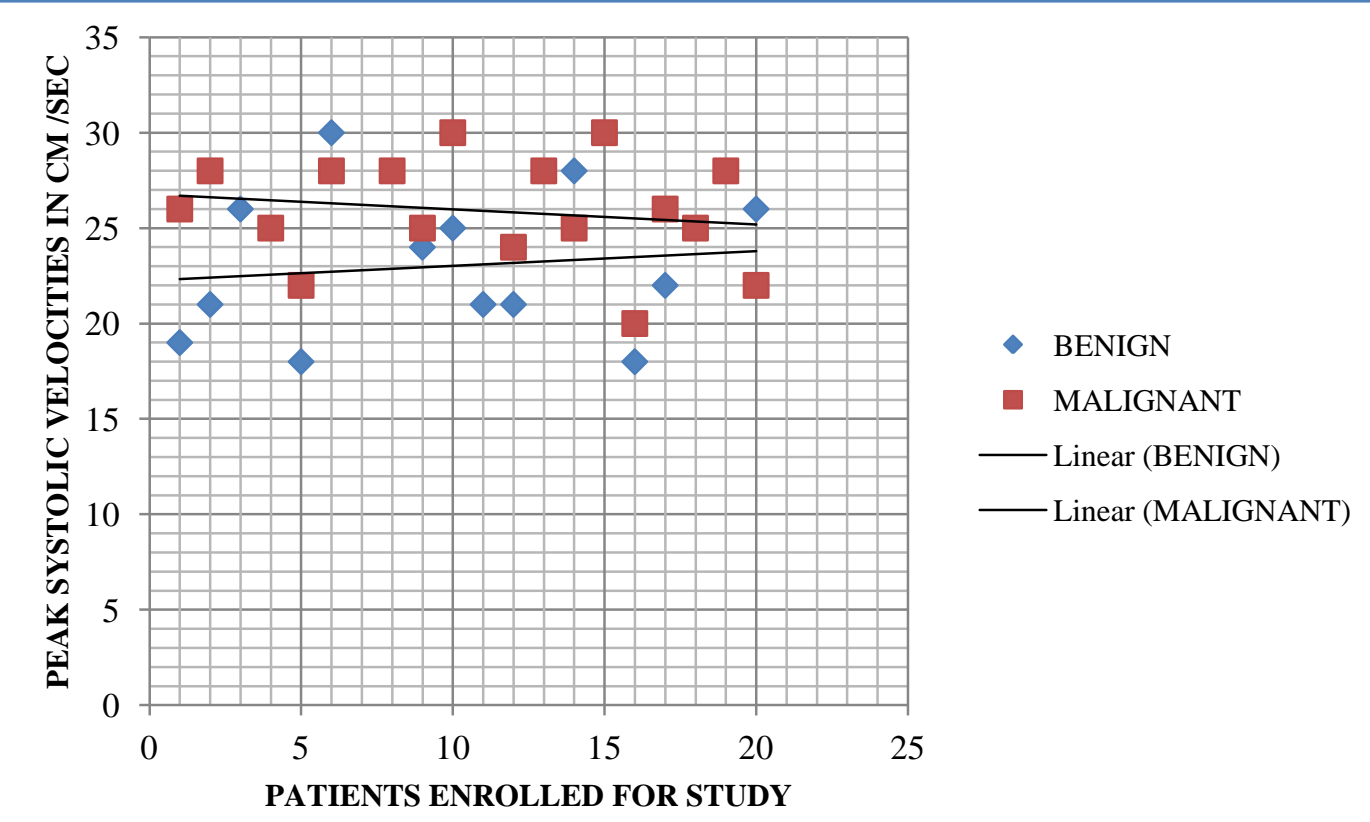


Table: Age in Years

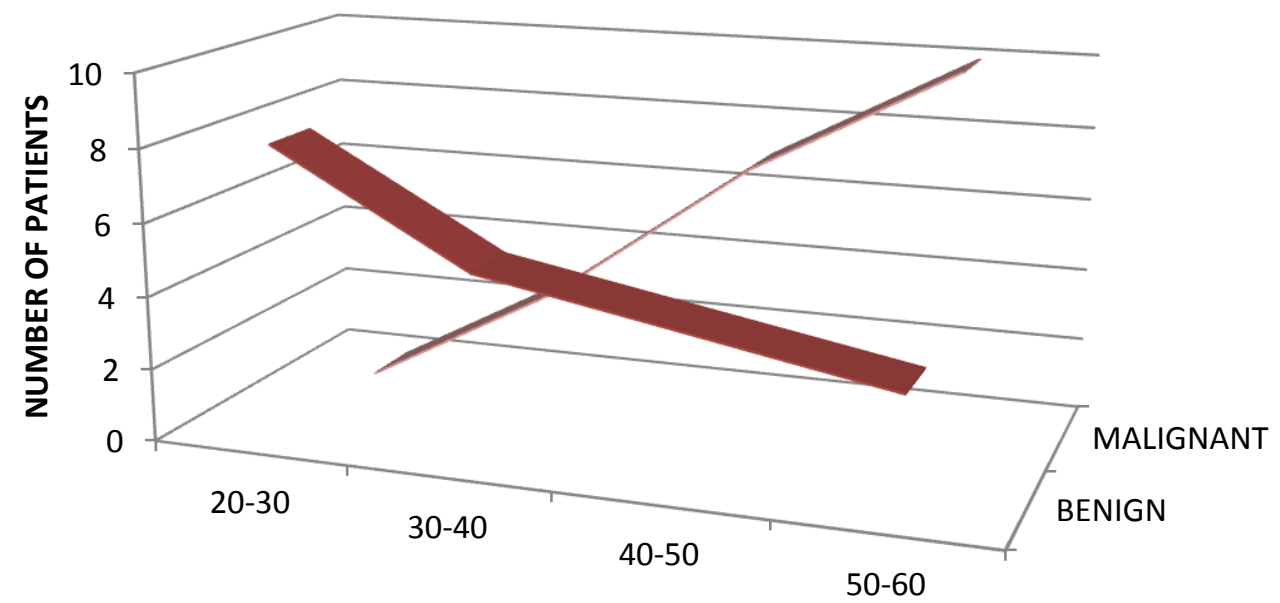

AGE IN YEARS

BENIGN $\square$ MALIGNANT

\section{Discussion}

Women in our study sample were subjected to clinical examination, digital mammography, ultrasound examination, CDUS and finally the imaging findings were correlated with the histopathology reports. Some of the essential Doppler criteria taken into consideration were 1.Whether vascularity is present /absent ${ }^{[13]} 2$.The morphology of vessels (smooth with regular branching / irregular or tortuous /chaotic) 3.distribution of vessels (central /peripheral, mixed, capsular) -whether the penetrating arteries are entering perpendicular to the mass, without crossing the capsular region or entering through the capsule ${ }^{[14]} 4$. Type of Doppler waveform (low impedance pulsatility, high impedance pulsatility, turbulent or continuous venous flow) 5.Number of feeding vessels within the lesion (1-2 arteries were referred to as hypovascular lesions, $>4$ arteries were identified as hypervascular lesions) ${ }^{[15]} 6$. Spectral analysis of the arteries using Peak Systolic Velocity (PSV) 7.Resistive Index (RI). Images were taken in various planes during real time imaging and stored in JPEG format.

\section{Conclusion}

Basically Color Doppler study is a safe, noninvasive modality and radiation free when compared to mammography for evaluation of palpable breast masses. Thus ultrasound along with Color Doppler Ultrasound is recommended as the prime screening tool for breast lesions in pregnant women, young women with high risk for breast cancer and those with dense breasts on mammogram. Indeterminate lesions with higher RI values, PSV values along with hyper vascularity favour the diagnosis of malignancy in cases of diagnostic dilemmas while in cases with relatively lower RI values, low impedance flow with minimal vascularity we can be reassured of the benignity of the lesion.

Still more studies with bigger study population and taking into account some more Doppler parameters using multivariate logistic regression are essential to give a better insight.

\section{Bibliography}

1. Stavros AT: Breast Ultrasound (1st Edition). Lippincott Williams \& Wilkins, PA, USA (2004).

2. Wells PT, Halliwell M, Skidmore R, Webb AJ, Woodcock JP: Tumour detection by ultrasonic Doppler blood-flow signals. Ultrasonics 15, 231-232 (1977).

3. Minasian H, Bamber JC: A preliminary assessment of an ultrasonic Doppler 
method for the study of blood flow in human breast cancer. Ultrasound Med. Biol. 8, 357-364 (1982).

4. Giuseppeti GM, Baldassarre S, Marconi E: Color Doppler sonography. Eur. J. Radiol. 27, S254-S258 (1998).

5. Athanasiou A, Tardivon A, Ollivier L et al.: How to optimize breast ultrasound. Eur. J. Radiol. 69(1), 6-13 (2009).

6. Catalano O, Raso MM, D'Aiuto M et al.: Additional role of colour Doppler ultrasound imaging in intracystic breast tumours. Radiol. Med. 114(2), 253-266 (2009).

7. Cosgrove D, Kedar R, Bamber JC et al.: Breast diseases: color Doppler US in differential diagnosis. Radiology 189, 99104 (1993). \&One of the first works regarding the use of color Doppler in breast.

8. Sehgal C, Arger $\mathrm{P}$, Rowling $\mathrm{S}$ et al.: Quantitative vascularity of breast masses by Doppler imaging: regional variations and diagnostic implications. J. Ultrasound Med. (19), 427-440 (2000).

9. Raza S, Baum J: Solid breast lesions: evaluation with power Doppler US. Radiology (203), 164 (1997). nn One of the first articles regarding the use of power Doppler in breast lesions.

10. Ozdemir A, Ozdemir H, Maral I et al.: Differential diagnosis of solid breast lesions: contribution of Doppler studies to mammography and gray scale imaging, J. Ultrasound Med. 20(10), 1091-1101 (2001).

11. Buadu L, Murakami J, Murayama S et al.: Colour Doppler sonography of breast masses: a multiparameter analysis. Clin. Radiol. 52(12), 917-923 (1997).
12. delCura JL, Elizagaray E, Zabala R et al.: The use of unenhanced Doppler sonography in the evaluation of solid breast lesions. Am. J. Roentgenol. 184(6), 1788-1794 (2005).

13. Kwak JY, Kim EK, Kim MJ et al.: Power Doppler sonography: evaluation of solid breast lesions and correlation with lymph node metastasis. Clin. Imaging 32(3), 167171 (2008).

14. Yang WT, Tse GM, Lam PK et al.: Correlation between color power Doppler sonographic measurement of breast tumor vasculature and immunohistochemical analysis of microvessel density for the quantitation of angiogenesis. J. Ultrasound Med. 21(11), 1227-1235 (2002).

15. Du J, Li FH, Fang H et al.: Microvascular architecture of breast lesions: evaluation with contrast-enhanced ultrasonographic micro flow imaging. J. Ultrasound Med. 27(6), 833-842 (2008). 